\title{
Reducing Negative Outcomes of Online Consumer Health Information: Qualitative Interpretive Study with Clinicians, Librarians, and Consumers
}

Reem El Sherif ${ }^{1}, \mathrm{MBBCh}, \mathrm{MSc}$; Pierre Pluye ${ }^{1}, \mathrm{MD}, \mathrm{PhD}$; Christine Thoër ${ }^{2}, \mathrm{PhD}$; Charo Rodriguez ${ }^{1}, \mathrm{MD}, \mathrm{PhD}$

${ }^{1}$ Department of Family Medicine, McGill University, Montreal, QC, Canada

${ }^{2}$ Department of Social and Public Communication, University of Quebec in Montreal, Montreal, QC, Canada

Corresponding Author:

Reem El Sherif, MBBCh, MSc

Department of Family Medicine

McGill University

Suite 300

5858 Chemin Cotes-des-Neiges

Montreal, QC, H3S 1Z1

Canada

Phone: 15146323616

Email: reem.elsherif@mail.mcgill.ca

\section{Abstract}

Background: There has been an exponential increase in the general population's usage of the internet and of information accessibility; the current demand for online consumer health information (OCHI) is unprecedented. There are multiple studies on internet access and usage, quality of information, and information needs. However, few studies explored negative outcomes of OCHI in detail or from different perspectives, and none examined how these negative outcomes could be reduced.

Objective: The aim of this study was to describe negative outcomes associated with OCHI use in primary care and identify potential preventive strategies from consumers', health practitioners', and health librarians' perspectives.

Methods: This included a two-stage interpretive qualitative study. In the first stage, we recruited through a social media survey, a purposeful sample of $19 \mathrm{OCHI}$ users who had experienced negative outcomes associated with OCHI. We conducted semistructured interviews and performed a deductive-inductive thematic analysis. The results also informed the creation of vignettes that were used in the next stage. In the second stage, we interviewed a convenient sample of 10 key informants: 7 health practitioners (3 family physicians, 2 nurses, and 2 pharmacists) and 3 health librarians. With the support of the vignettes, we asked participants to elaborate on (1) their experience with patients who have used OCHI and experienced negative outcomes and (2) what strategies they suggest to reduce these outcomes. We performed a deductive-inductive thematic analysis.

Results: We found that negative outcomes of OCHI may occur at three levels: internal (such as increased worrying), interpersonal (such as a tension in the patient-clinician relationship), and service-related (such as postponing a clinical encounter). Participants also proposed three types of strategies to reduce the occurrence of these negative outcomes, namely, providing consumers with reliable OCHI, educating consumers on how to assess OCHI websites, and helping consumers present and discuss the OCHI they find with a health professional in their social network or a librarian for instance.

Conclusions: We examined negative outcomes associated with using OCHI from five complementary perspectives (consumers, family physicians, pharmacists, nurses, and health librarians). We identified a construct of OCHI use-related tension that included and framed all negative outcomes. This construct has three dimensions (three interdependent levels): internal, interpersonal, and service-related tensions. Future research can focus on the implementation and effectiveness of the proposed strategies, which might contribute to reducing these tensions.

(J Med Internet Res 2018;20(5):e169) doi: 10.2196/jmir.9326

\section{KEYWORDS}

consumer health information; internet; professional-patient relations; qualitative research 


\section{Introduction}

\section{Online Consumer Health Information}

Online consumer health information (OCHI) is defined as information on health and diseases that is created for and directed to the general public [1]. General health information is available in written, audio, and video formats and freely accessible on government sites, professional organizations' websites, health journals, online forums, and blogs, among other sources. Moreover, consumers actively use social media to facilitate self-care, as well as being passively exposed to OCHI posts being shared by their social network through social media platforms such as Facebook [2,3].

American surveys of representative samples of the population have shown that the use of OCHI has increased dramatically over the last decade, and the internet is now the most popular source of consumer health information, whereas the use of other sources has decreased [4,5]. Reasons for this are the sheer volume of readily accessible health information available online, the increased engagement of people in their own health and self-care, and decreased access to health care services [6-8].

Increased access to $\mathrm{OCHI}$ is generally associated with increased consumer engagement in their own health care, increased empowerment of themselves and their families, and improved health outcomes [9-11]. Indeed, one of the most common ways consumers use OCHI is for consultation with health practitioners, for engagement in their own health care, compliance with or modification of management plan, or support of relatives or friends with health conditions [12]. There may, however, be some unintended negative consequences that are poorly understood and perhaps under reported [13,14]. With the increasing amount of OCHI available and the exponential increase in OCHI use, these negative consequences may also increase. The aim of this study was to identify and understand these negative outcomes from the viewpoint of primary care consumers and practitioners and try to find ways to reduce them.

\section{Literature Review}

Although there is evidence available on OCHI use and its outcomes in primary care, few studies have focused on the possible negative outcomes. In 2015, we conducted a systematic mixed studies review that examined outcomes associated with OCHI in primary care [15]. This review included 65 studies [15]. Although most of these studies reported positive outcomes (eg, reduced worries, increased satisfaction with health care services, increased involvement in decision making, and improvement of health), 23 studies described negative outcomes associated with using OCHI from either a physician or a patient perspective. One of the most well-known negative outcomes mentioned by both parties is increased anxiety, sometimes referred to as cyberchondria by researchers. Although physicians perceive this anxiety as excessive or overestimated, it is a reported consequence of looking for and using OCHI [16,17]. Another commonly reported outcome found in our review is deterioration in the patient-clinician relationship, especially after the patient shares the retrieved OCHI with a clinician [14]. A third outcome is the effect of using OCHI on the health care system resources, for example, leading to longer, unnecessary encounters with the family physician [18].

Most of the studies in our review were set in an oncology or public health setting and focused on specialized information (as opposed to general) or specific patient populations (eg, pregnant women) [19]. This is problematic as not all results from a specialist setting or tertiary health care population are transferrable to a primary care setting.

Figure 1. Conceptual framework.

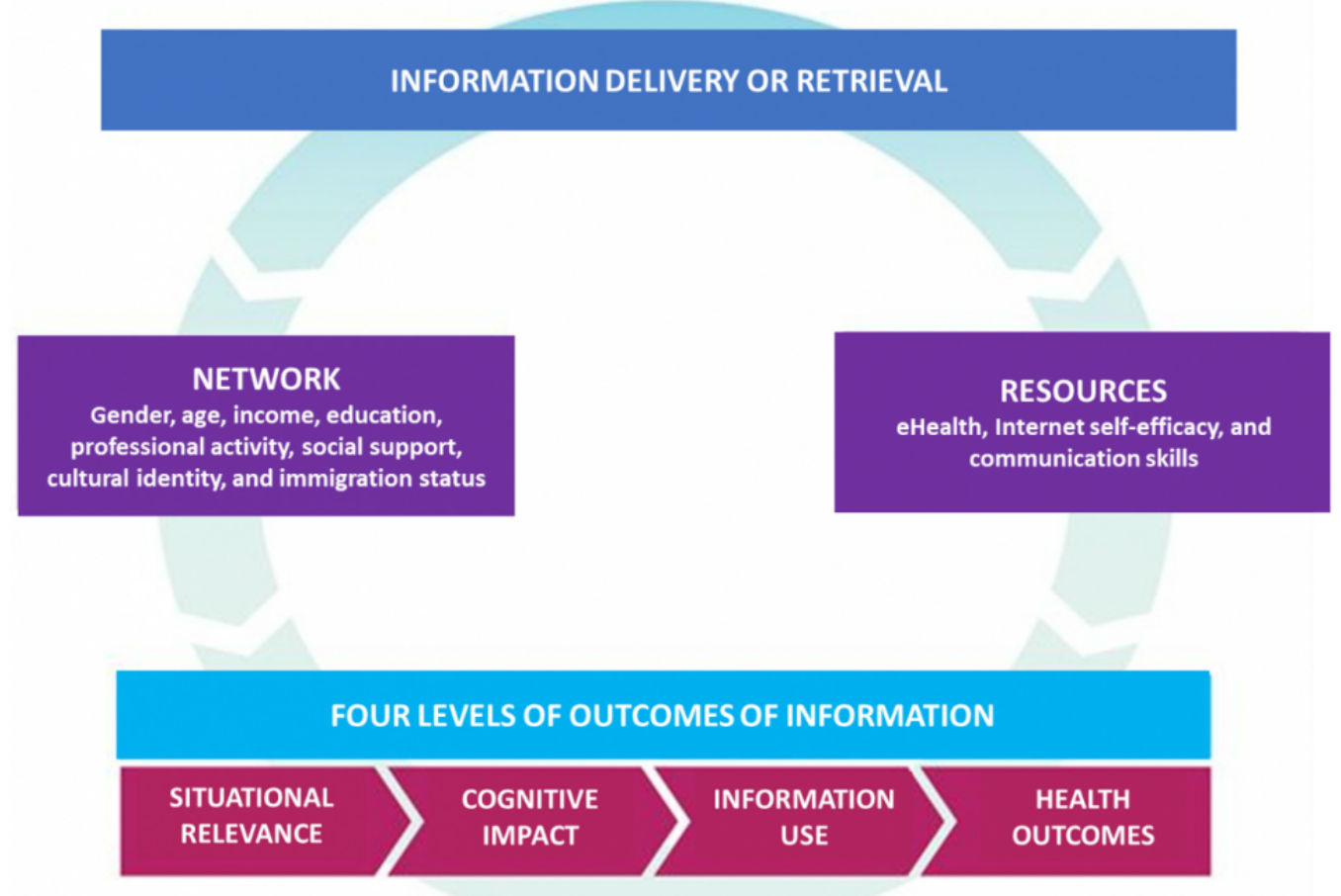




\section{Objectives}

The research question that guided this study was as follows: what are the negative outcomes of OCHI, and how can they be reduced? More specifically, we aimed to reach the following two objectives: (1) to identify and understand the meaning of the negative outcomes associated with OCHI use from consumers', health practitioners', and librarians' viewpoints in primary care and (2) to report means to reduce these negative outcomes proposed by consumers, health practitioners, and librarians.

\section{Conceptual Framework}

Our conceptual framework (Figure 1) [20] includes four levels of outcomes of information delivery and retrieval [12,21]: situational relevance, cognitive impact and use, and health or well-being outcomes of information. These levels are defined in relation to a specific information-seeking context: eg, a Web page used in a patient-clinician encounter. This framework was used to develop the interview guides and guided the deductive data analysis.

\section{Methods}

\section{Study Design}

We conducted a two-stage exploratory interpretive qualitative study that allows researchers "to obtain straight and largely unadorned answers to questions of special relevance to health care providers (HCPs) or policy makers" [22]. Methods and results are reported using the consolidated criteria for reporting qualitative studies [23]. We received ethical approval from the McGill University Faculty of Medicine's Research Ethics Office (institutional review board) before we started recruitment

\section{Stage 1-Consumers}

\section{Sampling}

We used a purposive sampling strategy to find participants who had experienced negative outcomes after using OCHI for themselves. Using a short online survey on SurveyMonkey (Multimedia Appendix 1) as a recruitment tool on social media platforms (Facebook and LinkedIn), we found a broad range of potential cases [24]. Some of the reported benefits of using Facebook to recruit participants include "reduced costs, shorter recruitment periods, better representation, and improved participant selection in young and hard to reach demographics" [25].

We received 148 completed surveys; 75 respondents indicated that they had experienced both positive and negative consequences of using OCHI and agreed to be contacted. These respondents were emailed a consent form by order of response (five per day) until data saturation was reached.

\section{Data Collection}

To accommodate the participants' time constraints and geographic dispersion, we used semistructured telephone interviews. Telephone interviews encourage a more explicit description of the participant's emotional experiences because of the absence of visual cues [26]. We developed an interview guide based on our conceptual framework, pilot-tested it for clarity, and modified it accordingly (Multimedia Appendix 2). Participants were asked to elaborate on their negative experience with OCHI use by telling their story and what factors they believe may have led to these outcomes. They were also asked what they think could have been done to prevent these outcomes. The 10-20 min interviews were recorded and conducted from November 2015 to February 2016. Interviews were transcribed verbatim (using pseudonyms to protect identities), and the transcripts were imported into the NVivo 11 software package (QSR International Pty Ltd, Victoria, Australia) for qualitative data analysis. Interviewing continued until data saturation was reached after 19 participants [27].

\section{Data Analysis}

A deductive-inductive analytical approach was adopted for coding [28]. We created a coding manual of the types of use and types of outcomes, both positive and negative, and the codes were discussed with the team until a consensus was reached. The codes were then progressively clustered into major themes. We also performed a secondary analysis of the interview transcripts using a story telling technique [29]. This involved viewing the interview transcript through multiple lenses and developing interpretive stories based on those lenses [30]. These stories, or vignettes, were created to represent each of the different types of negative outcomes identified in the literature review and the interviews. In stage 2 of this study, these stories were used to introduce the topic to the health practitioners and health librarians.

\section{Stage 2-Health Professionals}

\section{Sampling}

In stage 2, we selected seven health practitioners (three family physicians, two registered nurses, and two community pharmacists) and three health librarians because they are considered a primary source of health information for their patients [31]. These participants are considered key informants on the measures that could be taken to prevent negative consumer outcomes [27].

We used a purposeful sample of these key informants in Montreal and Ottawa. Using personal contacts in the Department of Family Medicine and the School of Information Studies at McGill, the Herzl Family Medicine Clinic, the Jewish General Hospital, and the Canadian Pharmacists Association of Canada, we invited primary care practitioners and health librarians to participate by email.

\section{Data Collection}

We conducted in-person semistructured interviews, 45 and 60 min in length, from March 2016 to April 2016. All the interviews were conducted at the participant's office (either in a clinic or hospital). We developed the interview guide based on our conceptual framework, pilot-tested it for clarity, and modified it accordingly (Multimedia Appendix 2). At the beginning of the interview, three vignettes created from the stage 1 interviews were presented to the stage 2 participants (Textbox 1). 
Textbox 1. Vignettes presented at the start of the interview with health care practitioners and health librarians.

\section{Vignette 1}

A young 22-year-old woman who identifies herself as a "bit of a hypochondriac" usually goes online to look for health information when she has multiple symptoms and she is unsure if they are related or not. She uses information to decide if she needs to see a doctor or not.

On one occasion, she had pain near her ribs and pain with "breathing." After checking online, she found "scary" diagnoses of similar symptoms and decided to go to the emergency room. After waiting there for a few hours, she was told it was nothing and went home. This happened a few times.

She feels that if there was more specific information online, or lists of the "most common diagnoses" for each symptom, she would worry less about her online findings.

Vignette 2

Mark is a 32-year-old man who usually looks for health information online when he has a new unfamiliar symptom. He uses information to decide whether (or not) he needs to see a doctor and to find possible explanations for his symptoms. The information helps him reflect on his lifestyle and determine if there are any changes he needs to make.

On one occasion, after suffering from abdominal pain for months, his family physician requested an ultrasound. During the ultrasound, and after some probing from Mark, the ultrasound technician suggested it may be a polycystic kidney causing his pain. As his follow-up appointment with the specialist was weeks away, Mark decided to do as much research on the topic as possible, which led to increasing anxiety over this diagnosis. Eventually at his appointment, the specialist diagnosed him with a failed kidney and not polycystic kidneys, which while severe, was still a relief for Mark.

Although in this case Mark blames the technician for making an unfounded diagnosis, he feels doing so much research on the topic allowed him to have an educated discussion with the specialist during his appointment.

\section{Vignette 3}

Sarah is a 26-year-old woman who was diagnosed with epilepsy. Her doctor prescribed Depakene as the best treatment, and she started using it. Then she started getting side effects from this medication.

After looking online for health information on this issue, she found that there were complementary and alternative treatments for epilepsy such as reiki and yoga, as well as herbal remedies, dietary supplements, and homeopathic treatments. She read testimonies by other people who had used these alternatives other than the Depakene and decided to perhaps try following them instead.

She feels that the information she found was biased, "you find what you look for." She admits that while looking for information, she might have valued a lot less information that said she needed to take the Depakene and valued more heavily information that said epilepsy was potentially manageable alternative and homeopathic remedies.

The vignettes offered the practitioners and librarians with an opportunity to reflect on the negative outcomes resulting from OCHI use and refreshed their memories of their own experiences. They were then asked to give their opinion on the situations described in the vignettes, as well as elaborate on their own experience with consumers or patients using OCHI. Finally, practitioners were asked what strategies they used to prevent or alleviate negative outcomes in their practice, whereas health librarians were asked what strategies they believe should be used to prevent negative outcomes. The interviews were conducted, transcribed, and analyzed two at a time [27]. No new codes emerged during the analysis of the 9th and 10th interviews, so data collection stopped.

\section{Data Analysis}

Using NVivo 11, we coded the transcripts for types of negative outcomes and preventive measures. Similar to the first stage, a deductive-inductive analytical approach was adopted [27]. We created a coding manual of the types negative outcomes and preventive measures, and the codes were discussed with the team until a consensus was reached. The codes were then progressively clustered into major themes.

\section{Results}

\section{Overview of the Results}

A description of the participants of both stages is presented in Tables 1 and 2. In both stages, many positive outcomes of OCHI were found: OCHI allows consumers to be informed and involved in their health care. According to participants, consumers have different strategies for finding and assessing $\mathrm{OCHI}$ and that factors such as health literacy and access to an $\mathrm{HCP}$ influence the type of outcome that occurs. Participants of both stages described similar negative outcomes such as increased worrying and postponing a health care visit. Preventive strategies mentioned in both stages included providing reliable sources of OCHI, teaching consumers to properly assess OCHI found, and discussing OCHI with someone else.

\section{How Consumers Find, Understand, and Use Online Consumer Health Information}

Consumers described their motivations and strategies for searching for OCHI, their understanding of the information they found, and how they used it. The identified themes and subthemes are described in Table 3. In summary, participants would most commonly search for information for themselves or for someone else by entering their symptoms into a search engine ("Googling their symptoms"). They had different ways of deciding the credibility of a website, and for the most part, just wanted more information on an issue, though some participants used OCHI to decide whether or not to book an appointment with a HCP or stop a medication, as illustrated in the following quote:

I've looked up stuff like side effects of birth control pills if I'm worried or more emotional, I'll see if that is one. I've actually gone off [pills] because of that. [Jenny] 
Table 1. Participants in stage 1.

\begin{tabular}{|c|c|c|}
\hline Pseudonym & Gender & Age group (years) \\
\hline Alan & Male & $18-24$ \\
\hline Betty & Female & $18-24$ \\
\hline Cara & Female & $18-24$ \\
\hline Dina & Female & $18-24$ \\
\hline Ella & Female & $18-24$ \\
\hline Fred & Male & $18-24$ \\
\hline Gina & Female & $18-24$ \\
\hline Harry & Male & $25-34$ \\
\hline Isabel & Female & $45-54$ \\
\hline Jenny & Female & $18-24$ \\
\hline Karen & Female & $18-24$ \\
\hline Lara & Female & $25-34$ \\
\hline Mariah & Female & $18-24$ \\
\hline Nathan & Male & $18-24$ \\
\hline Pamela & Female & $18-24$ \\
\hline Rita & Female & $18-24$ \\
\hline Sarah & Female & $18-24$ \\
\hline Tamara & Female & $18-24$ \\
\hline Vanessa & Female & $25-34$ \\
\hline
\end{tabular}

Table 2. Participants in stage 2.

\begin{tabular}{lll}
\hline Alias & Profession & Work environment \\
\hline Pharmacist \#1 & Clinical pharmacist & A family medicine clinic attached to a teaching hospital in Montreal. \\
Pharmacist \#2 & Community pharmacist & A community pharmacy and a family medicine clinic in Ottawa. \\
Doctor \#1 & Family physician & An academic hospital and a walk-in clinic in Montreal. \\
Doctor \#2 & Family physician & An academic hospital and a walk-in clinic in Montreal. \\
Doctor \#3 & Family physician & A family medicine clinic in Ottawa. \\
Librarian \#1 & Health librarian & A hospital health sciences library in Montreal. \\
Librarian \#2 & Health librarian & A hospital health sciences library in Montreal. \\
Librarian \#3 & Health librarian & A children's hospital health sciences library in Montreal. \\
Nurse \#1 & Nurse & An academic hospital in Montreal. \\
Nurse \#2 & Nurse practitioner & A family medicine clinic affiliated with an academic hospital in Montreal. \\
\hline
\end{tabular}


Table 3. Finding, understanding, and using online consumer health information (OCHI).

\begin{tabular}{ll}
\hline Theme and subtheme & Example quote
\end{tabular}

\section{Motivation for searching for health information online}

1.1 Searching for information for themselves

1.2 Hypochondria

1.3 Searching for information for someone else

\section{Strategies for searching for information online}

2.1 Using a search engine (Google)

2.2 Using a renowned medical website

2.3 Using websites or forums with patient experiences

2.4 Strategies for evaluating OCHI websites

\section{Making sense of the information}

3.1 Understanding the information found

3.2 Gaining general knowledge without answering a specific question

3.3 Not finding the answer to a specific health question

3.4 How health literacy influences understanding

\section{Decision making after finding relevant $\mathrm{OCHI}$}

4.1. Deciding whether or not to book a medical appointment

4.2 Postponing a medical appointment because of limited access

4.3 Making a health care decision

4.4 Stopping a medication

4.5 Discussion in a physician encounter

4.6 To confirm a physician's diagnosis
"When it is something that I cannot explain, like I have multiple symptoms and I don't know if all these symptoms are related, unrelated..." [Alan]

"I'm a little hypochondriac, I mean literally last night I was feeling nauseous, so I started to Google, so anytime I'm feeling an odd symptom....anytime I feel something is abnormal and I'll look up those symptoms to see if I have anything, from nausea and headaches to weird circulatory feelings." [Rita]

"Last time I looked up stuff online was for my grandfather. He suffered from Parkinson's...and we were looking for alternatives." [Nathan]

"I usually Google either my symptoms if I don't know what it is, or if I have an idea of what it might be then I'll Google that." [Betty]

"I just Google but the ones I usually end up in are WebMD or mayo clinic, I think if you Google something those are the first ones that show up anyway." [Rita]

"...there are a lot of useful forums where experienced marathoners have training advice, stuff like that. When to do icing or heat, which one is better than the other." [Ella]

"I usually avoid sites that are trying to sell you stuff or that anyone can edit." [Tamara]

"I understand it, I might have to do further research for specific terms, but overall I understand what they're saying." [Alan]

"Sometimes you don't know what is wrong or right and each case is different as well, so you have an idea globally, but you don't really have the answer I guess." [Mariah]

"No. I would have a symptom and it would usually end with me convincing myself that I had some sort of terminal illness." [Cara]

"No, I can usually understand it. I feel like I may be more science and health literate than a lot of people since I have a Bachelor's degree in Science." [Betty]

"I wouldn't say immediately but when I have a recurring kind of problem, so I'll look at it probably before calling the doctor and making an appointment." [Isabel]

"It's not even that, it's that you have to wait so long now to get an appointment that if I can home remedy it that's how I sort of look at it." [Isabel]

“Usually if it's something like I can change what I'm eating, I follow if it doesn't seem to extreme or too hard to do. If it's something that seems a bit ridiculous then..." [Tamara]

"I've looked up stuff like side effects of birth control pills if I'm worried or more emotional, I'll see if that is one. I've actually gone off [pills] because of that." [Jenny]

"Some things I'll bring up when seeing my physician and get their advice on it." [Dina]

"Yes, I have symptoms and look them up and if I find what I think it is I go to the doctor and I'll let the doctor suggest on their own but I'll kind of suggest that this what I think it could be, could you confirm that for me or not?" [Sarah] 


\section{Health Care Practitioners' and Health Librarians' Experience With Online Consumer Health Information}

Stage 2 participants described their general opinion of OCHI, the types of OCHI they had encountered, and factors they believed influenced the outcomes of OCHI use. The identified themes and subthemes are described in Table 4.

All the participants had seen their patients, their clients, and their friends and family use OCHI and had used OCHI themselves in their own health care. They believed it was a permanent fixture and an inevitable presence in the health care system, as illustrated in the following quote:

For patients, "I saw this online" is the new "my friend told me," which I still see a lot with the elderly, although even the elderly are going online.

[Pharmacist \#2]

Participants had experiences with different formats and topics of OCHI depending on their profession, the location of their practice, and the types of patients or consumers they saw. Physicians reported dealing with diverse topics (eg, medications and their side effects, medical conditions, and diagnostic tests) from various sources (reviewed online medical resources, patient forums, blogs, etc). Nurses, on the other hand, are traditionally more involved in patient education, and therefore tend to be more exposed to OCHI on general health information rather than specific health conditions. Pharmacists were more exposed to OCHI covering medications and their side effects and herbal products or supplements. Health librarians are traditionally health information providers, so are not necessarily exposed to patients presenting them with OCHI. They were, however, very familiar with the different sources of OCHI available, specifically patient forums, and were aware of its pros and cons.

A recurrent theme during the interviews was the OCHI related to alternative and complementary medical treatments and therapies. Participants mentioned some specific examples where patients had read of an unconventional treatment for their condition online and wanted to find out if it was a viable alternative. Another theme that was brought up during the interviews was the antivaccine movement, and participants mentioned interactions with people about vaccinations for which there is conflicting OCHI.

\section{Negative Outcomes of Online Consumer Health Information}

We identified three negative outcomes of OCHI based on participants' use of it (Table 5). First, increased worrying as a result of finding "scary" or worse-case-scenario information that might or might not be relevant to their symptoms. Second, tension in the relationship with a family member because the latter's use of potentially harmful OCHI. Finally, postponing seeking medical help for a health problem, or to ignore their health problem altogether. 
Table 4. Health care practitioners' and health librarians' experience with online consumer health information (OCHI).

\begin{tabular}{ll}
\hline Theme and subtheme & Example quote \\
\hline 1. General opinion of participants on OCHI & $\begin{array}{l}\text { "And for patients, 'I saw this online' is the new 'my friend told me,' which I still see a lot with the } \\
\text { elderly, although even the elderly are going online." [Pharmacist \#2] }\end{array}$
\end{tabular}

\section{Types of $\mathrm{OCHI}$}

2.1 General health information

2.2 Forums and patient-sourced information

2.3 Alternative medicine information

2.4 Antivaccination information

\section{Factors influencing outcomes}

3.1 Individual characteristics

3.2 Information avoidant personalities

3.3 Access to health care services
"I once saw a patient who had a dry cough and nothing else and came into an appointment because her friend had posted on Facebook that she had pneumonia.” [Doctor \#3]

“There are a ton of forums online people talking about their personal experiences...you don't get that from your health professional, they don't know what it's like to live with a condition. So, it can be very helpful to see other people's experiences and it may give your ideas for alternative treatments." [Librarian \#1]

"I had a patient who was relatively healthy but had high blood pressure that he treated with valerian root he had read about online... and so I looked it up and there was no real evidence for its effect on blood pressure." [Nurse \#1]

"It's extremely frustrating because a lot of this antivaccine stuff is focused on really small risks and you have to acknowledge there might be risks and people tend to fixate on them, like there is mercury in vaccines, yes but there's mercury in food. So, it can be extremely time consuming to combat that. I think that topic is the biggest and most harmful." [Pharmacist \#2]

"Definitely low health literacy but there also really well-educated people who don't have a health background and can be quite susceptible to the alternative medicine stuff. In another clinic where I work we see a lot of new immigrants, a lot of them Arabic speaking, I can't work with them as much.” [Pharmacist \#2]

"I think if you know your patient and kind of know they're the type who would basically somaticize every side effect you're not going to go over them in as much detail, you will sort of down play them." [Nurse \#1]

“Just that in Montreal, I don't know exact numbers, but around 30-40\% of people don't have a family doctor, and the more vulnerable you are the more your access to good medical care decreases so I think that yes there are flaws to internet usage to access health care, but in a system where person-to-person health care is not good or easy to access, it may be the only resource that many people have available to them." [Doctor \#2] 
Table 5. Negative outcomes of online consumer health information (OCHI).

\begin{tabular}{|c|c|}
\hline Stage and subtheme & Example quote \\
\hline \multicolumn{2}{|l|}{ Stage 1: consumers } \\
\hline Increased worrying & $\begin{array}{l}\text { "Sometimes it is anxiety inducing. If you can't find something that's a good match for what symptoms } \\
\text { you're having or if you find something that is a good match that isn't so pleasant." [Betty] }\end{array}$ \\
\hline Tension with family members & $\begin{array}{l}\text { "One of my aunts takes online health info way too far, and everything online, she follows, it doesn't } \\
\text { matter where it's from which is horrible because the internet has all sort of things...for } 5 \text { years my } \\
\text { cousin's life had all the random health natural remedies online, never doctors, it was so bad. It was } \\
\text { disturbing when we found that when he would have an infection she wouldn't take him to a doctor } \\
\text { but make him drink honey...This situation caused stress between family members worried about the } \\
\text { information she used." [Vanessa] }\end{array}$ \\
\hline $\begin{array}{l}\text { Postponing (not seeking help for) a health } \\
\text { problem }\end{array}$ & $\begin{array}{l}\text { "All my symptoms match a virus going around I read about it and I thought it will, blow over in a } \\
\text { week, I don't need to miss class to go to a doctor's appointment and then I ended up going to the } \\
\text { doctor and it ended up being an ear infection and a sinus infection and it turned into } 2 \text { months of } \\
\text { being miserable..." [Ella] }\end{array}$ \\
\hline \multicolumn{2}{|l|}{ Stage 2: practitioners and librarians } \\
\hline Increased worrying & $\begin{array}{l}\text { "Yeah, I think so, she was worried, she took time off work to come in to see me, and she waited in } \\
\text { the waiting room for a while. So, I have to take her worry seriously. This applies to many patients } \\
\text { I see, where there are no actually worrisome symptoms, if they had waited a few days whatever } \\
\text { they had would have gone away on its own. But they had read something online either after Googling } \\
\text { their symptoms or after accidentally stumbling on a piece of online information through social media } \\
\text { for example, and they worry they might have that." [Doctor \#3] }\end{array}$ \\
\hline Spending money on nonbeneficial products & $\begin{array}{l}\text { "A lot of the herbal and complementary and alternative therapy stuff, the biggest harm to a lot of } \\
\text { people is that it costs money and might not work... BP: I think the main consequence is that they } \\
\text { can't afford, it's common for people who are poor to have poor literacy so will believe all this stuff } \\
\text { they read online or Dr. Oz, so they end up spending money that they shouldn't be spending." } \\
\text { [Pharmacist \#2] }\end{array}$ \\
\hline Tension in the provider-patient relationship & $\begin{array}{l}\text { "I want them to know that I'm aware of it, that I'm not ignorant, because a lot of time this OCHI } \\
\text { can undermine their trust in your ability and your competence and they will say why didn't you tell } \\
\text { me about this? And sometimes the reason we haven't told is because we think that it will just scare } \\
\text { them which is true, and we do." [Nurse \#1] }\end{array}$ \\
\hline Nonadherence to management plan & $\begin{array}{l}\text { "I think one of the biggest ones, the area I've had most problems with is mental health, it's a huge } \\
\text { issue and affects a particular anxiety, a patient who is going through a lot of problems unfortunately } \\
\text { the internet and their ability to get information is a major block to being treated. They would look } \\
\text { up the side effects of the medications because they are more suggestible, experience every side effect } \\
\text { of the medication and eventually stop it." [Nurse \#1] }\end{array}$ \\
\hline Postponing seeking medical help & $\begin{array}{l}\text { "We had a gentleman come in here [health library] and he was looking for information, and he } \\
\text { started discussing what was wrong with him and saying he felt numbness in his leg and I said imme- } \\
\text { diately let me get you a wheelchair and transport you to the emergency room. He was asking me } \\
\text { for info about something that I clearly couldn't solve, and part of my job is identifying when } \\
\text { someone comes to me and saying you should go see a doctor or go to the emergency room." [Librar- } \\
\text { ian \#2] }\end{array}$ \\
\hline
\end{tabular}

Similar to the first stage, increased worrying was a negative outcome found in stage 2 (Table 5). This could stem from reading reliable but nonrelevant information, from reading too much information, or from finding incorrect information from unreliable websites. It was advice on these latter websites that led to the second negative outcome: the purchase of useless or potentially harmful medications online. A third negative outcome is the breakdown of trust in the patient-clinician relationship from, for example, clinicians not validating patients' information-seeking efforts. Moreover, finding information that contradicted that provided by the health practitioner also led to a breakdown in trust and lowered adherence to the management plan.

\section{Tension: A Comprehensive and Meaningful Construct}

On further examination of these outcomes, they appeared to fall under one main theme of tensions, with three dimensions, depending on who or what was being affected by OCHI use: internal, interpersonal, and service-related (summarized in Table $6)$.

\section{Strategies for Reducing Online Consumer Health Information Negative Outcomes}

Stage1 participants identified strategies that they used or believed would be helpful, such as managing expectations when searching for health information online, using reliable OCHI sources provided or reviewed by health practitioners, and discussing the information found with a health practitioner to validate its reliability and relevance to their health question. These strategies are presented in Table 7. 
Table 6. Online consumer health information (OCHI) tensions.

\begin{tabular}{lll}
\hline Levels & Stage 1: consumers & Stage 2: practitioners and librarians \\
\hline Internal tensions & Increased worrying & Increased worrying; Spending money on nonbeneficial products \\
Interpersonal tensions & Tension with family members & Tension in the provider-patient relationship \\
Service-related tensions & Ignoring (not seeking help) for a health problem & Nonadherence to management plan; Postponing seeking medical help
\end{tabular}

Table 7. Strategies for reducing negative outcomes of online consumer health information (OCHI).

Stage and subthemes $\quad$ Example quote

\section{Stage 1: consumers}

Be aware of limitations of OCHI

Reliable and relevant sources of OCHI

Follow physician-provided OCHI or search parameters

Discuss OCHI with physician, telehealth, or members of social network

\section{Stage 2: practitioners and librarians}

Provide reliable sources of OCHI

Teach people how to evaluate $\mathrm{OCHI}$

Discuss OCHI during a clinical encounter Nonadherence to management plan

Handling OCHI on alternative treatments or nonconventional therapies
"You have to be careful, when you do a Google search you get a ton of stuff there and sometimes rewording your search you get different things, so you want to be reading the same thing and not doing something that could do more damage than good." [Isabel]

"I think there are already doctors online, but I don't know maybe something more precise because Web MD can be precise but it's not that precise, like you can have just normal back pain and it will direct you to kidney failure.” [Lara]

"...but also, if there is a 2-week delay between getting a scan and seeing the professional about something that is serious, you should be provided with, you know, here are search parameters that you should look up that are neutral and that might give you content to reflect on so that you have an informed discussion with your doctor..." [Harry]

"I keep in mind that it's on the internet, so if I was really stressed I would go talk to a real person. I am skeptical of the information so if I was worried I would go talk to a doctor." [Jenny]

"Look it's there, so instead of resisting it, let's provide high quality alternatives so we have a little more control." [Librarian \#1]

"I think that if more health care providers used the approach of showing people where they look for info and pointing out potential issues with their sources and that is very effective, but it is time consuming." [Pharmacist \#2]

"I’ve mostly had a more positive experience just by being open and discussing it." [Nurse \#1]

"I think one of the biggest ones, the area I've had most problems with is mental health, it's a huge issue and affects a particular anxiety, a patient who is going through a lot of problems unfortunately the internet and their ability to get information is a major block to being treated. They would look up the side effects of the medications because they are more suggestible, experience every side effect of the medication and eventually stop it." [Nurse \#1]

"For the third vignette, we certainly don't discourage exploration into complementary and alternative treatments, we have an excellent evidence based database we can search that have knowledge synthesis of the research that shows whether a given alternative treatment is actually effective, so we could have looked at maybe different remedies to show if there is any solid evidence and if it actually works and maybe there's definitely bias." [Librarian \#1]

Table 8. Preventive strategies.

\begin{tabular}{lll}
\hline Strategies & Stage 1: consumers & Stage 2: practitioners and librarians \\
\hline Before OCHI ${ }^{\text {a }}$ search: providing reliable sources & $\begin{array}{l}\text { Be aware of limitations of OCHI; Reliable and } \\
\text { relevant sources of OCHI; Follow physician- } \\
\text { provided OCHI or search parameters }\end{array}$ & $\begin{array}{l}\text { Provide reliable sources of OCHI } \\
\begin{array}{l}\text { During the search: teaching consumers how to } \\
\text { evaluate OCHI sources }\end{array}\end{array}$ \\
$\begin{array}{l}\text { After finding relevant OCHI: discussing the in- } \\
\text { formation found }\end{array}$ & $\begin{array}{l}\text { Discuss OCHI with physician, telehealth, or } \\
\text { members of social network }\end{array}$ & $\begin{array}{l}\text { Discuss OCHI during a clinical encounter; Han- } \\
\text { dling OCHI on alternative treatments or noncon- } \\
\text { ventional therapies }\end{array}$ \\
\hline
\end{tabular}

${ }^{\mathrm{a} O C H I}$ : online consumer health information.

Similar strategies were also proposed by stage 2 participants to reduce the occurrence of negative outcomes. First, they recommended providing reliable OCHI sources. Second, teach consumers how to assess websites, either during an appointment or by referring them to online resources. Third, encourage consumers to discuss the OCHI with an HCP during a clinical 
encounter to validate its reliability and relevance. Our findings suggest this may be important for OCHI about alternative and complementary therapies, where it is important to explain to consumers the difference between regulated and unregulated therapies, as well as how to assess the reliability of the information found. Finally, our results suggest that because of the frequency of OCHI use, HCPs should be trained to deal with patients who bring $\mathrm{OCHI}$ to a clinical visit. These strategies are presented in Table 7.

Participants also suggested discussing OCHI with health librarians as they are well situated to provide reliable OCHI sources, teach consumers how to evaluate websites, help consumers prepare the information to discuss during a clinical encounter, and find reviewed evidence on complementary and alternative therapies.

In summary, many preventive strategies were proposed by participants to reduce the occurrence of negative outcomes, as shown in Table 8 . These include providing reliable OCHI sources before consumers start the search, teaching consumers to evaluate websites, and encouraging consumers to validate the information's reliability and relevance with an HCP.

\section{Discussion}

\section{Principal Findings}

Our findings confirm that OCHI is a part of daily routines in today's health care processes. It is a common, if not the most frequent, source of health information for consumers and is an integral part of the health care decision-making process. Congruent with existing evidence on OCHI, the outcomes of using $\mathrm{OCHI}$ are generally positive, especially when information sources are reliable. However, negative outcomes were reported consistently in terms of tensions across this study: the literature review, consumers in stage 1 , and health practitioners and librarians in stage 2 .

\section{Online Consumer Health Information Use-Related Tensions}

Elaborating on the Merriam-Webster dictionary definition of tension, the term OCHI tension refers to the feeling of uneasiness people who actively search for online health information experience with themselves, with other people, as well as vis-à-vis the health care services. Therefore, we argue that tension is a comprehensive and meaningful construct that represents a variety of negative outcomes along three dimensions. [33].

\section{Level 1: Internal Tensions}

These are outcomes that affect the consumer alone because of seeking and using OCHI and are associated with an emotional state. Internal outcomes uncovered in this study include increased worrying and anxiety. It has been suggested that "challenge and confusion, and dealing with the familiar and with the contradictory, are sources or triggers of emotional behavior in information situations" [33]. Moreover, with some consumers' lack of theoretical knowledge and ability to critically evaluate the information, this will inevitably lead to misinterpretation and unnecessary fear and anxiety [34].
Consumers who have even moderate levels of health anxiety are more likely to seek higher amounts of OCHI and spend more time online for health purposes overall [35,36]. One influencing factor is the individual's proneness to worry; one study examining the relationship between anxiety sensitivity and OCHI use reported that there was a relationship between exposure to $\mathrm{OCHI}$ and the etiology and maintenance of anxiety sensitivity [37].

\section{Level 2: Interpersonal Tensions}

Interpersonal tensions include any strain in the relationship between the OCHI consumer and other individuals, such as their HCP or a family member. An example of how this strain in the patient-clinician relationship occurs is when the practitioner does not acknowledge or validate the information brought in by their patient. A lack of trust developed when patients found information online that their HCP had not mentioned during the clinical encounter. This has also frequently been reported in the literature: patients who have read health information online may give less credence to their doctor's opinion and may use the information to test their doctor's knowledge, causing damage to the patient-clinician relationship [34,38]. On the other hand, some doctors lack the communication skills or are not up to date on all the information available and thus, report difficulties in dealing with OCHI.

\section{Level 3: Service-Related Tensions}

These tensions refer to any strain in the relationship between an OCHI consumer or patient and the health care system, leading to a change in the individual's use of health care services or adherence to management plans. This is in line with results reported in other studies. In one study, over $11 \%$ of the respondents reported that finding health information online led to them refusing or discontinuing treatment recommended by a physician or dentist [39]. Other studies also reported that participants (35\% and $29.9 \%$ ) would use the internet as a health information source instead of getting a professional opinion $[40,41]$. On the other hand, it was also reported that OCHI could lead to more frequent encounters with their HCP based on the information found [41].

On the basis of this construct of tension, we conceive the $O C H I$ use-related tensions as presented in Figure 2. This enriches our original conceptual framework and adds to the scientific knowledge on the outcomes of OCHI use [15]. In the literature, there is an established link between health anxiety (internal tension) and the patient-clinician relationship (interpersonal tension). Health anxious people are more prone to wrong self-diagnosis and unnecessary worries, which is likely to increase the risk of misunderstanding and frustration with their doctor [35]. They may also feel that the duration of the clinical encounter was not enough to discuss all their worries and be less satisfied with the consultation [32]. Moreover, there are studies that report a link between low trust in the physician (interpersonal tension) and nonadherence or mal-adherence to a management plan (service-related tension) [42]. Our results suggest there is a relationship between the three dimensions of tension. 
Figure 2. Online consumer health information (OCHI) use-based tensions.

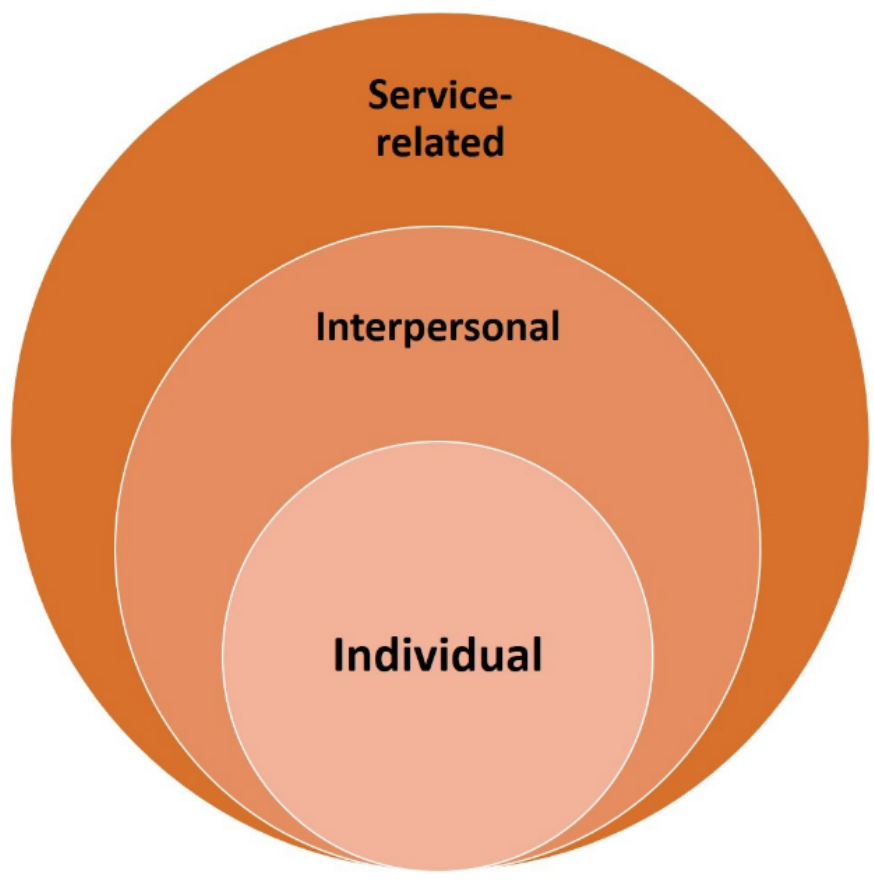

\section{Potential Preventive Strategies}

Several strategies targeting different periods of the iterative information-seeking process have been identified: before seeking the information online, while searching for information online, and after finding the information online. They can be summarized into three main preventive strategies as shown in Figure 3. During data analysis, it became clear that the health librarian participants in the second stage provided a distinct separate viewpoint and played a very different role from health practitioners.

\section{Before Online Consumer Health Information Search: Providing Reliable Sources}

Health practitioners preemptively provide patients with the names of reliable, reviewed websites during the clinical encounter rather than wait for patients to navigate on their own. This is in line with other studies that recommend that HCPs, specifically doctors, guide patients to reliable sources of OCHI [34,43-45]. Inevitability, people will try to search for health information online; however, they may not be adequately equipped to deal with the vast number of OCHI resources. In one study, even physicians expressed a need for training on how to navigate OCHI resources so that they are better able to recommend websites to their patients [46].

\section{During the Search: Teaching Consumers How to Evaluate Online Consumer Health Information Sources}

In the literature, it has been reported that evaluation interventions led to a more critical evaluation of online information [47]. This education process, however, is time-consuming and may not be a priority during the clinical encounter. Although practitioners could provide their patients with a list of criteria for reliable websites, there are also online resources available in the form of guidelines and checklists to follow while evaluating a website. However, many consumers, especially those in a lower socioeconomic strata, may not be aware of these resources or the fact that they are not correctly evaluating resources [48]. As suggested by participants in this study, an organizational effort is needed, for example, through mass media, in school curriculums, or in public libraries.

\section{After Finding Relevant Online Consumer Health Information: Discussing the Information Found}

The final strategy is discussing the information found with a health professional (eg, someone in their social network or a nurse phone line). This is supported by the literature; it was reported that patients simply need to have the information they found explained, contextualized, or validated by a health practitioner $[34,40]$. Studies report that discussing the information they had found with their physicians had a positive effect on the patient-clinician relationship, led to more involvement in decision making, and led to reduction of worries [32].

For health practitioners, there are ongoing initiatives to add OCHI into their continuing education (eg, workshops on dealing with their informed patients). For consumers, there are initiatives to encourage them to discuss information with their providers either through the help of a health librarian who can help organize the information and questions, or applications and websites that aid in that role (eg, the webpage Discutons Sante). There are, however, limitations to discussing OCHI; time limitations during the clinical encounter, and there may be a barrier related to practitioner attitudes. There may also be a barrier in understanding the health information (because of low health literacy or low education) or a limited social network. 
Figure 3. Strategies to reduce online consumer health information (OCHI) tensions.

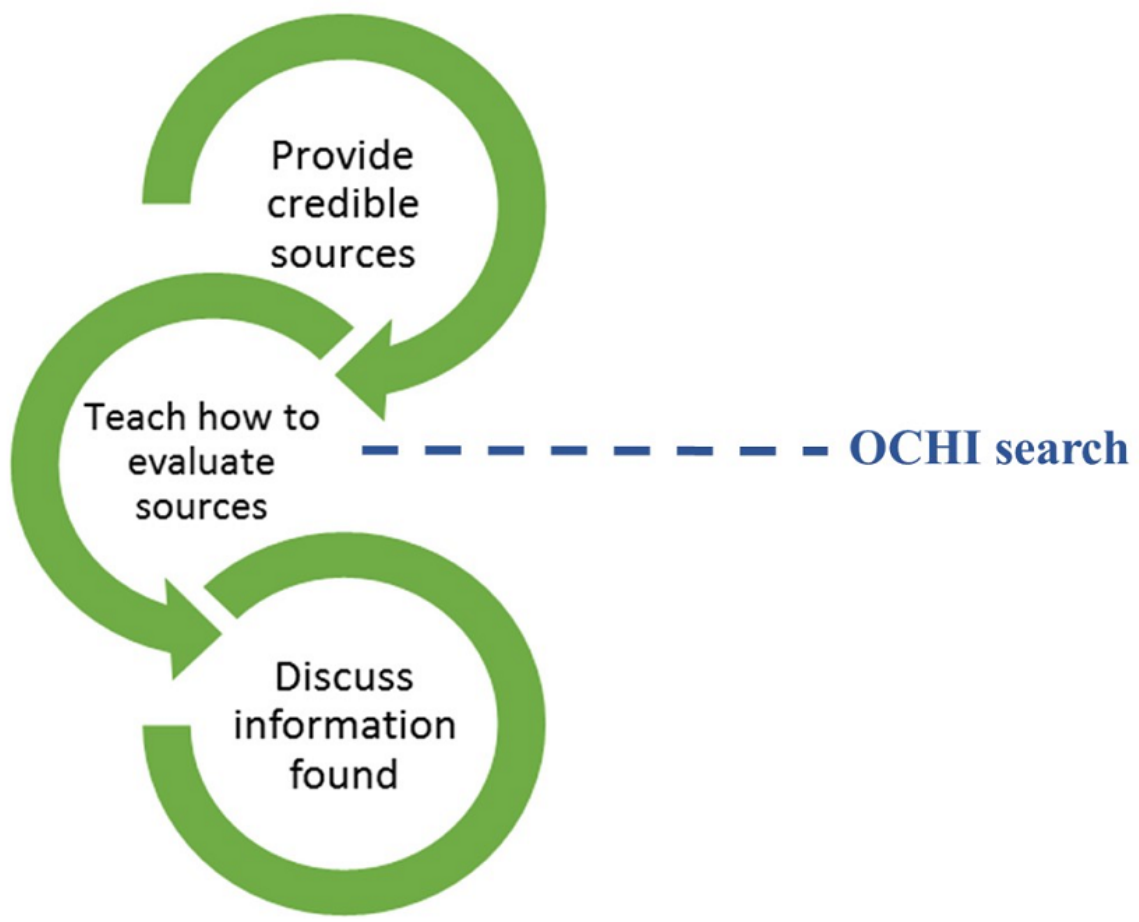

\section{The Key Role of Librarians}

Librarians are responsible for providing reliable health information and advocating the advantages of using OCHI for informed decision making. Working with consumers and health practitioners, they are well positioned to implement the preventive strategies described in this study. The integration of health librarians into the consumer's health information-seeking process may help ensure the reliability of the OCHI they find and use, as well as the appropriateness of its level of health literacy, leading to fewer internal tensions. Librarians' involvement may facilitate the discussion with health practitioners, leading to fewer interpersonal tensions. Finally, they can help consumers find situationally relevant OCHI, helping them to make more appropriate health care decisions and potentially leading to fewer service-related tensions.

Two barriers to the integration of health librarians into this information-seeking process should be noted: the lack of awareness of available health librarian services and the lack of access to health librarians by the public (because of their location inside hospitals). One potential solution would be to train community librarians working in public libraries on how to provide health information services and instruction, or at least train them to refer consumers to the local hospital-based health librarian.

\section{Strengths and Limitations}

Most respondents in stage 1 were females in the age range of 18 to 24 years. Although the lack of heterogeneity of our sample may present a limitation, studies report that the majority of individuals who search for and used OCHI are young women, which is reflected in our sample [40,49]. A recent systematic review on the use of Facebook in recruiting participants for health research purposes suggests that using social media to recruit participants may have led to this young female population sample [25]. A future study could use other recruitment tools to focus on an older population and to explore differences. One strength of our study is that our participants were all key informants, purposefully sampled for their experience and knowledge on the topic, as well as their willingness to incorporate OCHI in their practice [27,50]. No new ideas emerged in the final few interviews, and there was corroboration after triangulation of results of the review and all interviews.

\section{Conclusions}

The purpose of this investigation was to describe the negative outcomes associated with using online consumer health information, as well as to identify and reflect on any potentially preventive strategies.

This work makes two major contributions to the advancement of knowledge on OCHI. The first concerns a fine-grained identification of OCHI negative outcomes, which results from the construct OCHI use-related tension with three different and noninclusive levels of tensions (dimensions): individual, interpersonal, and service-related. This original construct enriches the original conceptual framework on outcomes of OCHI use and can serve as a foundation for future research. The second contribution, which involves clear practical implications, refers to the strategies primary care consumers, community, and health librarians and all types of primary care practitioners could adopt to prevent the risks associated with OCHI use. Exploration of these strategies and their implementation will be part of our future research. 


\section{Acknowledgments}

The authors would like to acknowledge Paula Bush, Vera Granikov, and Quan Nha Hong for their participation and feedback throughout this project. This work was supported by the Canadian Institutes of Health Research (CIHR) operating grant KRS-132042. This project was conducted using CIHR funds for the Master's thesis project of RS.

\section{Authors' Contributions}

PP and CR were involved in all stages of the project and specifically in the data analysis. CT was a thesis committee member who provided feedback throughout the project. All authors participated in writing and revising the manuscript.

\section{Conflicts of Interest}

None declared.

\section{Multimedia Appendix 1}

Survey used as a recruitment tool.

[PNG File, 150KB-Multimedia Appendix 1]

\section{Multimedia Appendix 2}

Interview guides.

[PDF File (Adobe PDF File), 258KB-Multimedia Appendix 2]

\section{References}

1. HLWIKI Canada. 2015. Consumer health information URL: http://hlwiki.slais.ubc.ca/index. php?title=Consumer health information\&oldid=142405 [accessed 2018-03-07] [WebCite Cache ID 6xkVoWs1D]

2. Fox S, Jones S. Pew Internet. 2011 May 12. The Social Life of Health Information, 2011 URL: http://pewinternet.org/ Reports/2011/Social - Life - of - Health - Info.aspx [accessed 2018-03-07] [WebCite Cache ID 6xkQah0GD]

3. Hamm MP, Chisholm A, Shulhan J, Milne A, Scott SD, Given LM, et al. Social media use among patients and caregivers: a scoping review. Br Med J Open 2013;3(5):e002819 [FREE Full text] [doi: 10.1136/bmjopen-2013-002819] [Medline: $\underline{23667163]}$

4. Prestin A, Vieux SN, Chou WS. Is online health activity alive and well or flatlining? Findings from 10 years of the Health Information National Trends Survey. J Health Commun 2015 Jul;20(7):790-798. [doi: 10.1080/10810730.2015.1018590] [Medline: 26042588]

5. Jacobs W, Amuta AO, Jeon KC. Health information seeking in the digital age: An analysis of health information seeking behavior among US adults. Cogent Soc Sci 2017 Mar 13;3(1):1302785. [doi: 10.1080/23311886.2017.1302785]

6. Amante DJ, Hogan TP, Pagoto SL, English TM, Lapane KL. Access to care and use of the Internet to search for health information: results from the US National Health Interview Survey. J Med Internet Res 2015;17(4):e106 [FREE Full text] [doi: 10.2196/jmir.4126] [Medline: 25925943]

7. Prescott J, Mackie L. "You sort of go down a rabbit hole...you're just going to keep on searching": a qualitative study of searching online for pregnancy-related information during pregnancy. J Med Internet Res 2017 Jun 05;19(6):e194 [FREE Full text] [doi: 10.2196/jmir.6302] [Medline: 28583906]

8. Case DO, Given LM. Looking for Information: A Survey of Research on Information Seeking, Needs, and Behavior: 4th Edition. UK: Emerald Group Publishing Limited; 2016.

9. Coulter A. Patient engagement--what works? J Ambul Care Manage 2012;35(2):80-89. [doi: 10.1097/JAC.0b013e318249e0fd] [Medline: 22415281]

10. Edwards M, Davies M, Edwards A. What are the external influences on information exchange and shared decision-making in healthcare consultations: a meta-synthesis of the literature. Patient Educ Couns 2009 Apr;75(1):37-52. [doi: 10.1016/j.pec.2008.09.025] [Medline: 19036550]

11. Renahy E, Chauvin P. Internet uses for health information seeking: a literature review. Rev Epidemiol Sante Publique 2006;54(3):263-275. [Medline: 16902386]

12. Pluye P, Grad R, Repchinsky C, Jovaisas B, Johnson-Lafleur J, Carrier ME, et al. Four levels of outcomes of information-seeking: A mixed methods study in primary health care. J Am Soc Inf Sci Technol 2012 Dec 10;64(1):108-125. [doi: 10.1002/asi.22793]

13. Berg K. University of Toronto Doctoral dissertations. 2011. Health Management in the Age of the Internet (Doctoral dissertation) URL: https://tspace.library.utoronto.ca/handle/1807/29663 [accessed 2018-04-03] [WebCite Cache ID 6yPPNHeQx] 
14. Iverson SA, Howard KB, Penney BK. Impact of internet use on health-related behaviors and the patient-physician relationship: a survey-based study and review. J Am Osteopath Assoc 2008 Dec;108(12):699-711. [Medline: 19075034]

15. Granikov V, El Sherif R, Tang DL, Bujold M, Frati F, Bartlett G, et al. What are the outcomes associated with the use of online consumer health information in primary health care? A systematic review with framework synthesis of quantitative and qualitative evidence. 2016 May Presented at: Joint Meeting of the Medical Library Association (MLA), the Canadian Health Libraries Association/Association des bibliothèques de la santé du Canada (CHLA/ABSC), and the International Clinical Librarian Conference (ICLC), Mosaic '16. J Can Health Libr Assoc; 2016; Toronto.

16. Lewis T. Seeking health information on the internet: lifestyle choice or bad attack of cyberchondria? Media Cult Soc 2006 Jul 01;28(4):521-539. [doi: 10.1177/0163443706065027]

17. White RW, Horvitz E. Cyberchondria: studies of the escalation of medical concerns in web search. ACM Trans Inf Syst 2009 Nov 01;27(4):1-37. [doi: 10.1145/1629096.1629101]

18. Ahmad F, Hudak PL, Bercovitz K, Hollenberg E, Levinson W. Are physicians ready for patients with Internet-based health information? J Med Internet Res 2006;8(3):e22 [FREE Full text] [doi: 10.2196/jmir.8.3.e22] [Medline: 17032638]

19. Burton-Jeangros C, Hammer R. [Information seeking on the internet: what information are pregnant women seeking?]. Rev Med Suisse 2013;9(383):895-897. [Medline: 23697085]

20. Saracevic T, Kantor P. Studying the value of library and information services Part 1. Establishing a theoretical framework. J Am Soc Inf Sci Technol 1997;48(6):527-542. [doi: 10.1002/(SICI)1097-4571(199706)48:6<527::AID-ASI6>3.0.CO;2-W]

21. Pluye P, Granikov V, Bartlett G, Grad RM, Tang DL, Johnson-Lafleur J, et al. Development and content validation of the information assessment method for patients and consumers. JMIR Res Protoc 2014 Feb 18;3(1):e7 [FREE Full text] [doi: 10.2196/resprot.2908] [Medline: 24550180]

22. Schwartz-Shea P, Yanow D. Interpretive Research Design: Concepts and Processes. UK: Routledge; $2013: 041587808$.

23. Tong A, Sainsbury P, Craig J. Consolidated criteria for reporting qualitative research (COREQ): a 32-item checklist for interviews and focus groups. Int J Qual Health Care 2007 Dec;19(6):349-357 [FREE Full text] [doi: 10.1093/intqhc/mzm042] [Medline: 17872937$]$

24. Merolli M, Gray K, Martin-Sanchez F. Developing a framework to generate evidence of health outcomes from social media use in chronic disease management. Med 20 2013;2(2):e3 [FREE Full text] [doi: 10.2196/med20.2717] [Medline: 25075238]

25. Whitaker C, Stevelink S, Fear N. The use of Facebook in recruiting participants for health research purposes: a systematic review. J Med Internet Res 2017 Aug 28;19(8):e290 [FREE Full text] [doi: 10.2196/jmir.7071] [Medline: 28851679]

26. Cachia M, Millward L. The telephone medium and semi - structured interviews: a complementary fit. Qual Res Org Manag Int J 2011 Nov 15;6(3):265-277. [doi: 10.1108/17465641111188420]

27. Sandelowski M. Sample size in qualitative research. Res Nurs Health 1995 Apr;18(2):179-183. [Medline: 7899572]

28. Fereday J, Muir-Cochrane E. Demonstrating rigor using thematic analysis: a hybrid approach of inductive and deductive coding and theme development. Int J Qual Methods 2016 Nov 29;5(1):80-92. [doi: 10.1177/160940690600500107]

29. Sandelowski M. Telling stories: narrative approaches in qualitative research. Image J Nurs Sch 1991;23(3):161-166. [Medline: 1916857]

30. McCormack C. From interview transcript to interpretive story: part 1-viewing the transcript through multiple lenses. Field Methods 2016 Jul 24;12(4):282-297. [doi: 10.1177/1525822X0001200402]

31. Medlock S, Eslami S, Askari M, Arts DL, Sent D, de Rooij SE, et al. Health information-seeking behavior of seniors who use the Internet: a survey. J Med Internet Res 2015;17(1):e10 [FREE Full text] [doi: 10.2196/jmir.3749] [Medline: 25574815]

32. Tanis M, Hartmann T, Te Poel F. Online health anxiety and consultation satisfaction: a quantitative exploratory study on their relations. Patient Educ Couns 2016 Dec;99(7):1227-1232. [doi: 10.1016/j.pec.2016.01.021] [Medline: 26873545]

33. Nahl D, Bilal D. Information and Emotion: The Emergent Affective Paradigm in Information Behavior Research and Theory. New Jersey: Information Today, Inc; 2007:1573873101.

34. Agius M, Stangeland H. How Does the Internet Influence the Doctor-Patient Relationship? In: e-Mental Health. Cham: Springer; 2016.

35. Singh K, Brown RJ. Health-related internet habits and health anxiety in university students. Anxiety Stress Coping 2014;27(5):542-554. [doi: 10.1080/10615806.2014.888061] [Medline: 24467278]

36. Eastin MS, Guinsler NM. Worried and wired: effects of health anxiety on information-seeking and health care utilization behaviors. Cyberpsychol Behav 2006 Aug;9(4):494-498. [doi: 10.1089/cpb.2006.9.494] [Medline: 16901253]

37. Norr AM, Capron DW, Schmidt NB. Medical information seeking: impact on risk for anxiety psychopathology. J Behav Ther Exp Psychiatry 2014 Sep;45(3):402-407. [doi: 10.1016/j.jbtep.2014.04.003] [Medline: 24818986]

38. Hewitt-Taylor J, Bond CS. What e-patients want from the doctor-patient relationship: content analysis of posts on discussion boards. J Med Internet Res 2012;14(6):e155 [FREE Full text] [doi: 10.2196/jmir.2068] [Medline: 23137788]

39. Weaver JB, Thompson NJ, Weaver SS, Hopkins GL. Healthcare non-adherence decisions and internet health information. Comput Human Behav 2009 Nov;25(6):1373-1380. [doi: 10.1016/j.chb.2009.05.011]

40. Fox S, Duggan M. Pew Internet. Health online 2013 URL: http://www.pewinternet.org/2013/01/15/health-online-2013/ [accessed 2018-03-07] [WebCite Cache ID 6xkQQbJPP] 
41. Beck F, Richard JB, Nguyen-Thanh V, Montagni I, Parizot I, Renahy E. Use of the internet as a health information resource among French young adults: results from a nationally representative survey. J Med Internet Res 2014;16(5):e128 [FREE Full text] [doi: 10.2196/jmir.2934] [Medline: 24824164]

42. Wroth TH, Pathman DE. Primary medication adherence in a rural population: the role of the patient-physician relationship and satisfaction with care. J Am Board Fam Med 2006;19(5):478-486 [FREE Full text] [Medline: 16951297]

43. Silver MP. Patient perspectives on online health information and communication with doctors: a qualitative study of patients 50 years old and over. J Med Internet Res 2015;17(1):e19 [FREE Full text] [doi: 10.2196/jmir.3588] [Medline: 25586865]

44. Iacovetto MC, Allen LA. Transitioning into a digital world: time for providers to recommend Internet health information? Am Heart J 2015 Jul;170(1):1-2. [doi: 10.1016/j.ahj.2015.04.002] [Medline: 26093858]

45. Pluye P, Grad R, Barlow J. Look It Up!: What Patients, Doctors, Nurses, and Pharmacists Need to Know about the Internet and Primary Health Care. Montreal: McGill-Queen's University Press; 2017.

46. van Uden-Kraan CF, Drossaert CH, Taal E, Smit WM, Seydel ER, van de Laar MA. Experiences and attitudes of Dutch rheumatologists and oncologists with regard to their patients' health-related Internet use. Clin Rheumatol 2010 Nov;29(11):1229-1236 [FREE Full text] [doi: 10.1007/s10067-010-1435-1] [Medline: 20383731]

47. Walraven A, Brand-Gruwel S, Boshuizen HP. Fostering transfer of websearchers' evaluation skills: a field test of two transfer theories. Comput Human Behav 2010 Jul;26(4):716-728. [doi: 10.1016/j.chb.2010.01.008]

48. Diviani N, van den Putte DB, Giani S, van Weert JC. Low health literacy and evaluation of online health information: a systematic review of the literature. J Med Internet Res 2015;17(5):e112 [FREE Full text] [doi: 10.2196/jmir.4018] [Medline: 25953147]

49. Bianco A, Zucco R, Nobile CG, Pileggi C, Pavia M. Parents seeking health-related information on the Internet: cross-sectional study. J Med Internet Res 2013;15(9):e204 [FREE Full text] [doi: 10.2196/jmir.2752] [Medline: 24047937]

50. Crouch M, McKenzie H. The logic of small samples in interview-based qualitative research. Soc Sci Inf 2006 Dec 01;45(4):483-499. [doi: 10.1177/0539018406069584]

\section{Abbreviations \\ HCP: health care provider \\ OCHI: online consumer health information}

Edited by L Buis; submitted 02.11.17; peer-reviewed by T Guetterman, S Koch-Weser; comments to author 21.11.17; revised version
received 31.01.18; accepted 09.03.18; published 04.05.18
Please cite as:
El Sherif R, Pluye P, Thoër C, Rodriguez C
Reducing Negative Outcomes of Online Consumer Health Information: Qualitative Interpretive Study with Clinicians, Librarians,
and Consumers
J Med Internet Res 2018;20(5):e169
URL: $\underline{\text { http://www.jmir.org/2018/5/e169/ }}$
doi: $\underline{10.2196 / j m i r .9326}$
PMID: 29728350

CReem El Sherif, Pierre Pluye, Christine Thoër, Charo Rodriguez. Originally published in the Journal of Medical Internet Research (http://www.jmir.org), 04.05.2018. This is an open-access article distributed under the terms of the Creative Commons Attribution License (https://creativecommons.org/licenses/by/4.0/), which permits unrestricted use, distribution, and reproduction in any medium, provided the original work, first published in the Journal of Medical Internet Research, is properly cited. The complete bibliographic information, a link to the original publication on http://www.jmir.org/, as well as this copyright and license information must be included. 